\title{
Cytotoxic T Cell Responses to Multiple Conserved HIV Epitopes in HIV-Resistant Prostitutes in Nairobi
}

\author{
Sarah L. Rowland-Jones, ${ }^{\star}$ Tao Dong, ${ }^{\star}$ Keith R. Fowke, ${ }^{\ddagger}$ Joshua Kimani, ${ }^{\S}$ Pete Krausa, ${ }^{\star}$ Heidi Newell, ${ }^{\star}$ Tom Blanchard, ${ }^{\star}$ \\ Koya Ariyoshi," Julius Oyugi, ${ }^{\S}$ Elizabeth Ngugi, ${ }^{\S}$ Job Bwayo, ${ }^{\S}$ Kelly S. MacDonald, ${ }^{\S \uparrow}$ Andrew J. McMichael, ${ }^{\star}$ \\ and Francis A. Plummer $\$$ \\ * Molecular Immunology Group, Institute of Molecular Medicine, John Radcliffe Hospital, Oxford OX3 9DS, UK; ${ }^{\ddagger}$ Department of \\ Medical Microbiology, University of Manitoba, Winnipeg, Manitoba, Canada R3E 0W3; \$epartment of Medical Microbiology, \\ University of Nairobi, Nairobi, Kenya; "MRC Unit, Fajara, The Gambia; and "Department of Medicine, University of Toronto, Mount \\ Sinai Hospital, Toronto, Ontario, Canada M5G 1 X5
}

\begin{abstract}
Many people who remain persistently seronegative despite frequent HIV exposure have HIV-specific immune responses. The study of these may provide information about mechanisms of natural protective immunity to HIV-1. We describe the specificity of cytotoxic $T$ lymphocyte responses to HIV in seronegative prostitutes in Nairobi who are apparently resistant to HIV infection. These women have had frequent exposure to a range of African HIV-1 variants, primarily clades $\mathrm{A}, \mathrm{C}$, and $\mathrm{D}$, for up to $12 \mathrm{yr}$ without becoming infected. Nearly half of them have CTL directed towards epitopes previously defined for B clade virus, which are largely conserved in the A and D clade sequences. Stronger responses are frequently elicited using the $A$ or $D$ clade version of an epitope to stimulate CTL, suggesting that they were originally primed by exposure to these virus strains. CTL responses have been defined to novel epitopes presented by HLA class I molecules associated with resistance to infection in the cohort, HLA-A*6802 and HLA-B18. Estimates using a modified interferon-gamma Elispot assay indicate a circulating frequency of CTL to individual epitopes of between 1:3,200 and 1:50,000. Thus, HIV-specific immune responses-particularly cross-clade CTL activitymay be responsible for protection against persistent HIV infection in these African women. (J. Clin. Invest. 102:17581765.) Key words: human immunodeficiency virus-specific cytotoxic T lymphocytes - AIDS in Africa - cross-clade immune responses
\end{abstract}

\section{Introduction}

There is increasing evidence that a substantial proportion of people with documented HIV exposure who remain uninfected generate a range of immune responses to the virus, which include Th-1 helper responses, cytotoxic $\mathrm{T}$ lymphocytes

S.L. Rowland-Jones and T. Dong contributed equally to this work. Address correspondence to Sarah Rowland-Jones, Molecular Immunology Group, Institute of Molecular Medicine, John Radcliffe Hospital, Oxford OX3 9DS, UK. Phone: 44-1865-222316; FAX: 441865-222502; E-mail: sarah.rowland-jones@ndm.ox.ac.uk

Received for publication 17 June 1998 and accepted in revised form 15 September 1998.

J. Clin. Invest.

(C) The American Society for Clinical Investigation, Inc. 0021-9738/98/11/1758/08 \$2.00

Volume 102, Number 9, November 1998, 1758-1765

http://www.jci.org
(CTL), ${ }^{1}$ and mucosal IgA secretion (1-3), while remaining negative for plasma HIV antibodies. It is not clear whether these immune responses constitute the means of protection against persistent HIV infection or are simply markers of previous exposure to infectious virus. The issue is important to resolve, since it has significant implications for vaccine design.

We previously described the finding of HIV-specific CTL restricted through HLA-B35 in a small group of persistently seronegative Gambian prostitutes; these women remain well and virus-negative by all available assays and continue to have demonstrable circulating CTL activity after several years of follow-up (4) (Dong, T., K. Ariyoshi, P. Krausa, D. Whitby, S. Sabally, T. Corrah, R. Weiss, H. Whittle, A.J. McMichael, and S.L. Rowland-Jones, manuscript submitted for publication). Although these women are presumed to have regular exposure to HIV-infected clients, the intensity of exposure is relatively low in The Gambia (where HIV seroprevalence is $~ 1-2 \%$ ) compared with other areas of sub-Saharan Africa. We now describe the detection of persistent CTL activity to a range of HIV epitopes in a group of seronegative women whose exposure to HIV is amongst the highest documented anywhere in the world. The women are part of a cohort of lower-class prostitutes working in the Pumwani-Majengo area of Nairobi, established in 1985 by the Universities of Nairobi and Manitoba (5). HIV seroprevalence in this cohort rose rapidly to $\sim 90-95 \%$; the rate of progression to AIDS in infected women is much shorter (median 3.5 years) than in Western cohorts (6). This may be a consequence of frequent episodes of sexually transmitted diseases and the absence of the protective CCR5 and SDF- $1 \alpha$ genotypes found in Caucasians (7). The exceedingly high HIV seroprevalence and incidence (up to $25 \%$ per year) imply particularly intense HIV exposure. A small proportion of the women have remained uninfected for up to $12 \mathrm{yr}$ of follow-up, and epidemiological studies in this group strongly suggest genuine resistance to infection (8). This cannot be ascribed to any identifiable behavioral or demographic factors; however, there are associations between resistance and susceptibility with certain class I and class II HLA haplotypes in this cohort (MacDonald, K.S., K.R. Fowke, J. Kimani, V.A. Dunand, N.J.D. Nagelkerke, T.B. Ball, J. Oyugi, E. Njagi, L. Gaur, R.C. Brunham, J. Wade, S.L. Rowland-Jones, E. Ngugi, J.J. Bwayo, and F.A. Plummer, manuscript submitted for publication). These include associations with protection of the class I A2-A*6802 supertype, individually, with the African subtypes of $\mathrm{A} 2$ and $\mathrm{A} 28, \mathrm{~A} * 0202$ and $\mathrm{A} * 6802$ and, less strongly, HLA-B18. HIV-specific Th-1 and bulk CTL responses have been reported in several members of the resis-

1. Abbreviations used in this paper: CTL, cytotoxic T lymphocyte; MVA, modified vaccinia Ankara. 
tant group (Fowke, K., K.L. Rosenthal, J. Kimani, W.J. Rutherford, N.J.D. Nagelkerke, J. Oyugi, T.B. Ball, J.J. Bwayo, J.N. Simonsen, and F.A. Plummer, manuscript submitted for publication).

We now describe the fine specificity of HIV-specific CTL elicited from these women, detected using direct stimulation of PBMCs with known CTL epitope peptides. These epitopes have previously been mapped in studies of predominantly Caucasian subjects infected with B clade HIV. The extent to which distinct HIV-1 strains from different parts of the world elicit cross-clade cellular immune responses has only recently been studied. HIV-1-specific CTL showing cross-reactivity against diverse HIV clades were detected in some (but not all) recipients of a clade B env-based vaccine (9). More recently, several studies demonstrated significant cross-clade CTL activity in HIV-infected patients, by using target cells infected with vaccinia expressing HIV genes of different clades and CTL cultured from B clade-infected Caucasians or African patients naturally infected with subtypes A, C, D, and G (10-12). To date, however, no CTL epitopes have been mapped for subtypes other than clade B (13). The women in this study are most likely to have been exposed to HIV-1 clades A, D, and C, the major strains in Nairobi, where $>70 \%$ of isolates are clade A (14); we have examined CTL responses to the A and D clade versions of less conserved epitopes.

An alternative mechanism of HIV resistance was described in exposed uninfected Caucasians who are homozygous for a 32-basepair deletion in the coding sequence of CCR-5 (CCR5$\Delta 32)$; this prevents cell-surface expression of the CCR-5 chemokine receptor, the principal coreceptor for primary HIV isolates (15). This genotype is strongly associated with persistent seronegativity in multiply exposed Caucasians (16-19) and was the first genetic factor shown to mediate resistance to HIV infection. Nevertheless, it is clear that the defect does not account for all cases of apparent HIV resistance, and it is largely confined to people of European descent (19-21). Parallel studies in this cohort show that cells from the women are fully infectible with a range of HIV isolates and that there are no abnormalities in full-length sequencing of the coding regions of their CCR5 and CCR3 genes (22). HIV-specific immunity may be more important than coreceptor polymorphism in mediating resistance to HIV infection in these African women.

\section{Methods}

\section{Donors and controls}

The study participants were selected from women in the Pumwani sex-worker cohort in Nairobi, Kenya, which was established in a collaboration between the Universities of Nairobi and Manitoba in 1985, as described (5).

The "resistant" women are defined as those remaining seronegative for $>3 \mathrm{yr}$ of follow-up. They remain healthy and persistently seronegative for HIV-1 (ELISA for HIV-1/2/0, Murex); repeated testing for HIV-1 proviral DNA by PCR (using specific primer sets for HIV-1 env, nef, and pol) has always been negative (8).

Control donors were laboratory workers in Oxford at low risk of HIV infection who were identified as having the same class I HLA alleles as those through which CTL responses had been detected in the Nairobi cohort.

The identification of new HLA-A*6802- and B18-restricted epitopes was carried out using CTL established from HIV-seropositive donors in Oxford, Nairobi, and The Gambia.
Donors were fully HLA-typed using ARMS-PCR with sequencespecific primers, as described (23).

\section{Epitope prediction and peptide synthesis}

Although the peptide-binding motif has not been determined for HLA-A $* 6802$, we used information about the $B$ and $F$ pocket residues to predict a motif identical to that determined for HLA-A69 (24), namely valine (V) or threonine (T) at P2 and V or leucine (L) at P9. A panel of 49 9-mer peptides was predicted from the A and D consensus sequences of HIV-1 gag, nef, and pol by using his motif.

The other peptides used were selected from a panel of previously defined B clade CTL epitopes (13) on the basis of the donors' class I haplotypes. Additional peptides representing the A and D clade sequences of these epitopes were also made. Peptides were synthesized by F-moc chemistry using a Zinnser Analytical synthesizer (Advanced Chemtech, Louisville, KY), and purity was established by HPLC. Peptides were dissolved in RPMI medium and concentrations were determined using a bicinchoninic acid (BCA) assay (Pierce \& Wariner, Chester, England).

\section{CTL studies}

Identification of HLA-A*6802-restricted epitopes by using HIV-specific CTL from infected donors. PBMCs were separated from the blood of HIV-1-infected donors with HLA-A*6802 (from The Gambia and Nairobi), and bulk cultures were established by restimulation with autologous PHA-stimulated lymphoblasts as described (25). CTLs were cultured in RPMI 1640 (Gibco Life Technologies, Glasgow, Scotland) with $10 \%$ FCS (Gibco Life Technologies), i.e., R/10, and antibiotics for $1 \mathrm{wk}$, with $10 \%$ Lymphocult $\mathrm{T}$ (Biotest, Solihull, England) for the second week. Standard ${ }^{51}$-chromium release assays were performed after $2 \mathrm{wk}$, using HLA-A*6802-matched or mismatched target B-lymphoblastoid cell lines labeled with ${ }^{51}$-chromium (Amersham, Buckinghamshire, England) and pulsed with pool of predicted $A * 6802$ epitope peptides or a control influenza peptide at $50 \mu \mathrm{M}$. If there was recognition of one of the peptide pools, the experiment was repeated using the individual peptides from the pool. The assays were counted on a flatbed scintillation counter (Wallac, Gaithersburg, MD). Background chromium release was always $<20 \%$. Percentage of lysis was calculated from the formula $100 \times(\mathrm{E}-\mathrm{M} / \mathrm{T}-\mathrm{M})$, where $\mathrm{E}$ is the experimental release, $\mathrm{M}$ is the release in the presence of $\mathrm{R} / 10$ medium, and $\mathrm{T}$ is release in the presence of $5 \%$ Triton $\mathrm{X}-100$ detergent. Results were regarded as positive if recognition of the HIV peptide was $>10 \%$ above that of a control peptide in at least two separate assays.

\section{CTL studies in the resistant cohort}

PBMCs were separated from 10-15 ml heparinized blood, and peptide-stimulated cultures were established using peptide epitopes selected according to the donor's class I HLA type (4). In brief, the cells were pulsed as a pellet for $1 \mathrm{~h}$ with $100 \mu \mathrm{M}$ of synthetic peptides representing previously defined optimized HIV-1 CTL epitopes, then diluted in R/10 to a final concentration of $10 \mu \mathrm{M}$, and cultured at 2 million cells per well in a 24-well Costar plate (Costar, Cambridge, MA). Recombinant IL-7 (a kind gift from Dr. Adrian Minty, Sanofi-Labege, Labege, France) was added to a concentration of $25 \mathrm{ng} / \mathrm{ml}$ at the start of the cultures; this facilitates the more efficient generation of specific CTL (26). IL-2, in the form of Lymphocult-T (Biotest), was added to a dilution of $10 \%$ on day 3 . Assays for specific CTL activity were carried out after 10-14 d in culture, by using autologous or HLA-matched target cells pulsed with the appropriate and control peptides.

Where there were no known epitopes for the donor's HLA haplotype, some CTL cultures were set up using modified vaccinia Ankara (MVA) expressing gag genes from A and D clade HIV-1 (Dorrell, L., C. O'Callaghan, W. Britton, S. Hambleton, A.J. McMichael, G.L. Smith, S.L. Rowland-Jones, and T. Blanchard, manuscript submitted for publication). The MVA was added directly to donor PBMC at 2 million cells per well in a 24-well Costar plate, at an moi of $1 \mathrm{pfu} / 30$ 
Table I. Recognition of Previously Defined Clade B HIV-1 CTL Epitopes in the Nairobi Cohort

\begin{tabular}{|c|c|c|c|c|c|c|}
\hline Donor & HLA type & Restriction & Protein & Clade A & Clade B & Clade D \\
\hline \multirow[t]{2}{*}{ ML 851} & A1, A*6802, & B7 (*8101) & gag & & SPRTLNAWV & \\
\hline & B8, B7 (*8101) & & nef & TPGPGIRYPL & TPGPGVRYPL & TPGPGIRYPL \\
\hline \multirow[t]{2}{*}{ ML 893} & A1, 24, B35, B63 & B35 & pol & HPDIVIYQY & NPDIVIYQY & NPEIVIYQY \\
\hline & & B35 & nef & & VPLRPMTY & \\
\hline ML 1192 & $A * 202$ & A2 & pol & ILKDPVHGV & ILKEPVHGV & \\
\hline \multirow[t]{2}{*}{ ML 1203} & $\mathrm{~A} 80, \mathrm{~A} * 6802$ & A*6802 & pol & DTVLEDINL & DTVLEEMNL & \\
\hline & $\mathrm{B} 7, \mathrm{~B} 42$ & B7 & nef & TPGPGIRYPL & TPGPGVRYPL & \\
\hline \multirow[t]{3}{*}{ ML 1250} & $A * 202, A 33$ & A33 & p24 & & IILGLNKIVR & \\
\hline & $\mathrm{B} * 5802, \mathrm{~B} 71$ & A2 & p17 & SLFNTVATL & SLYNTVATL & \\
\hline & & $\mathrm{A} 2$ & nef & ALKHRAYEL & AFHHVAREL & AFEHKAREM \\
\hline \multirow[t]{4}{*}{ ML 1362} & $\mathrm{~A} * 202, \mathrm{~A} 29$, & $\mathrm{A} 2$ & pol & ILKDPVHGV & ILKEPVHGV & \\
\hline & B47 & $\mathrm{A} 2$ & $\mathrm{P} 24$ & & TLNAWVKVV & \\
\hline & & $\mathrm{A} 2$ & p17 & SLFNTVATL & SLYNTVATL & \\
\hline & & A2 & pol & & VIYQYMMDL & \\
\hline \multirow[t]{2}{*}{ ML 1371} & A*201, *6802 & $\mathrm{A} 2$ & nef & ALKHRAYEL & AFHHVAREL & AFEHKAREM \\
\hline & B18, B45 & & & & & \\
\hline \multirow[t]{5}{*}{ ML 1490} & $\mathrm{~A} * 2301, \mathrm{~A} * 7401$ & B14 & pol & & VTDSQYALGI & \\
\hline & B*1402, B49 & B14 & gp41 & ERYLRDQQL & ERYLKDQQL & \\
\hline & & B14 & $\mathrm{p} 24$ & DRFFKTLRA & DRFYKTLRA & \\
\hline & & B14 & $\mathrm{p} 24$ & DLNNMLNIV & DLNTMLNTV & \\
\hline & & B49 & nef & & YPLTFGWCY & YPLTFGWCF \\
\hline \multirow[t]{2}{*}{ ML 1498} & $\mathrm{~A} 29, \mathrm{~A} * 6802$ & B14 & p24 & DRFFKTLRA & DRFYKTLRA & \\
\hline & B*1402, B57 & & & & & \\
\hline \multirow[t]{3}{*}{ ML 1524} & $A * 6802, A 30$ & B35 & gp41 & & TAVPWNASW & \\
\hline & B35, B42 & B35 & p24 & PPIPVGDIY & PPIPVGEIY & \\
\hline & & $A * 6802$ & pol & DTVLEDINL & DTVLEEMNL & \\
\hline
\end{tabular}

CTL were set up from 21 exposed seronegative donors by using the B clade peptide epitopes selected on the basis of class I haplotype. This table shows 10 donors and 20 epitopes for whom a positive response was elicited (defined as $>10 \%$ specific lysis on more than one occasion) and shows the extent of variation between the B clade sequence and that of the common Kenyan HIV-1 clades, A and D (substitutions are shown in bold).

cells, then $10 \%$ Lymphocult $\mathrm{T}$ was added from day 3 . The culture was tested for lysis of autologous target cells infected with MVA expressing either the relevant gag gene or a control protein from influenza, at an moi of $10 \mathrm{pfu} / \mathrm{cell}$.

\section{Elispot assays}

A modified Elispot assay to detect peptide-specific IFN- $\gamma$ release was carried out using either freshly separated or cryopreserved PBMC, as previously described $(27,28)$. In brief, 96-well nitrocellulose plates were coated with a first-layer antibody to IFN- $\gamma$ (Mabtech, Stockholm, Sweden); then PBMC were placed in the wells at three input concentrations $\left(2 \times 10^{5}, 10^{5}\right.$ and $\left.5 \times 10^{4}\right)$ in duplicate. Cells were pulsed with either no peptide or one of a panel of peptides selected according to the class I HLA-type of the donor, at a final concentration of $10 \mu \mathrm{M}$, and the plate incubated at $37^{\circ} \mathrm{C}, 5 \% \mathrm{CO}_{2}$ for $16 \mathrm{~h}$. The cells were then washed off and the plate was developed using detector and conjugate antibodies, followed by chromogen. The spots were counted by eye, and the numbers confirmed using a dissecting microscope.

Control assays were carried out under identical conditions by using cells from laboratory workers at low risk of HIV infection with the same class I alleles through which responses had been detected in the resistant cohort. Both HIV and appropriate EBV and influenza A CTL epitopes were used for the control assays, together with PHAactivated PBMCs to confirm cell viability.

\section{Results}

$C T L$ responses to conserved epitopes can be elicited using clade $B$ peptides. Molecular HLA typing of prostitutes who had been persistently seronegative throughout $3 \mathrm{yr}$ of follow-up revealed 21 women with at least one class I HLA molecule for which clade B HIV epitopes had previously been defined. CTL directed towards several of these epitopes were detected in 10 of these women after 10-14 d in vitro culture of their PBMCs with the appropriate peptide. Assays were regarded as positive if there was $>10 \%$ specific lysis of peptide-pulsed target cells at two different $\mathrm{E} / \mathrm{T}$ ratios in at least two separate experiments. Results were regarded as equivocal if specific lysis was over $10 \%$ in only one experiment or at $5-10 \%$ in two separate experiments.

The epitopes recognized and the extent of variation between them in the consensus sequences of clades A, B, and D are shown in Table I. Of the 20 epitopes recognized, 7 are conserved across the consensus sequences of clades A, B, and D. Only 2 show more than one amino acid substitution between the A and B clade sequences. It was possible to repeat studies in four women positive for CTL on the first testing after $18 \mathrm{mo}$; CTL of the same specificities were elicited in all four.

CTL were not elicited in seven women despite their having HLA types for which at least one CTL epitope had been described (e.g., HLA-A*0201, A*301). One had a strong A2restricted CTL response to an influenza A peptide but not to four different HIV epitopes. In the remaining women, assays were thought to be equivocal, i.e., peptide-specific lysis of $5-10 \%$ on more than one assay.

The same protocol was used with PBMC from 12 laboratory workers at low risk of HIV infection who had the appro- 

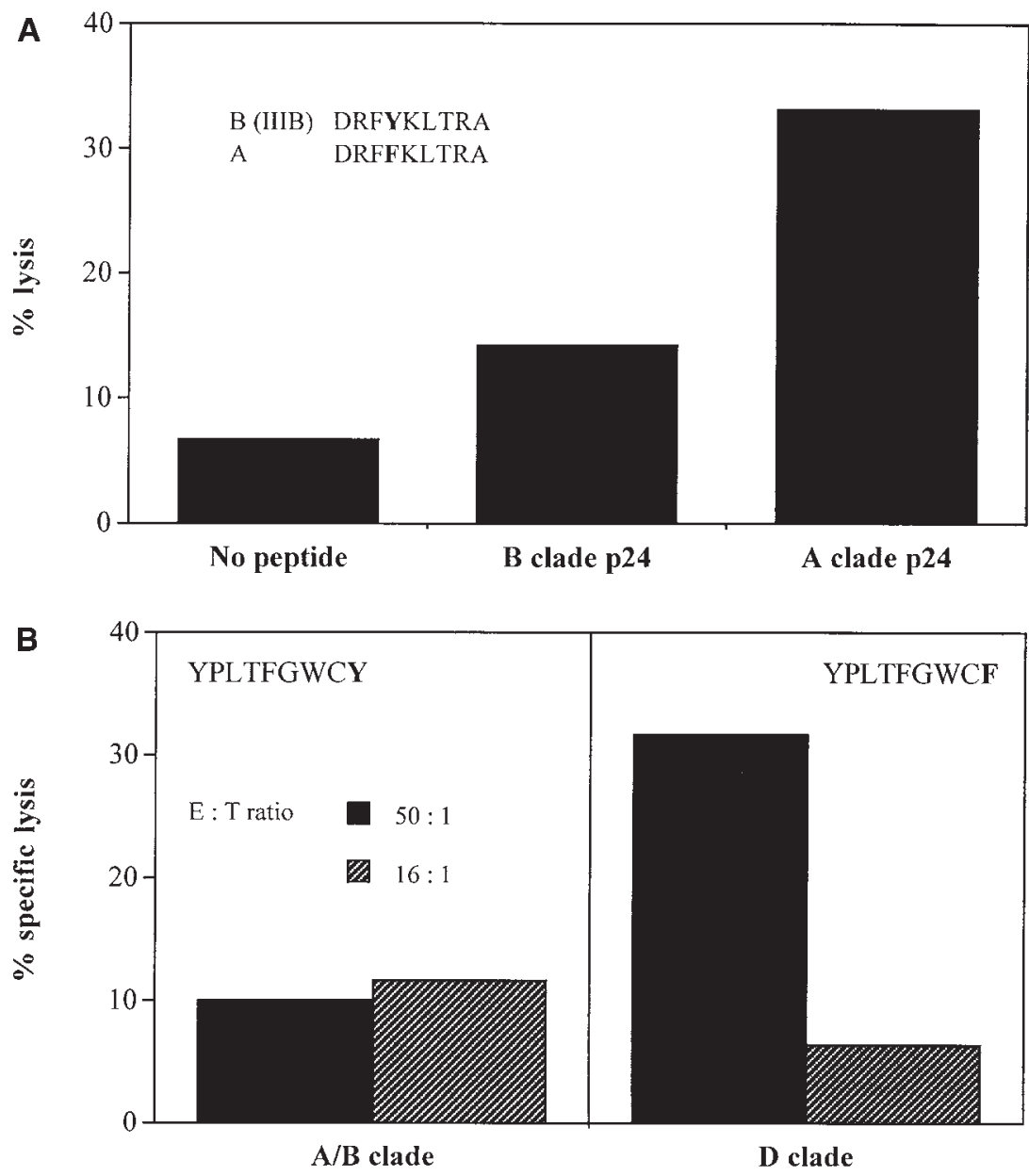

Figure 1. (A) CTL were established by stimulating PBMC from donor ML1490 (HLA$A * 2301, A * 7401, B * 1402$, B49) with a known B14restricted epitope from B-clade p24 gag. The CTL were then tested for recognition of autologous targets pulsed with either the B clade peptide or the A clade equivalent at $20 \mu \mathrm{M}$. The $\mathrm{E} / \mathrm{T}$ ratio was 12:1. (B) The specific lysis (with the no peptide control subtracted) at two E/T ratios of autologous targets pulsed with either the previously defined B49-restricted B clade nef epitope or the D clade equivalent (at $20 \mu \mathrm{M}$ ), using CTL from donor 1490 set up with the B clade peptide.

priate HLA alleles. No CTL were detected to a total of $14 \mathrm{HIV}$ peptides presented by HLA-A*0201, B7, B14, B18, and B35, although 4 gave A2-restricted influenza-specific responses, and 2 had B35-restricted EBV and influenza CTL.

Preferential recognition of $A$ and $D$ clade epitope sequences. For some donors, CTL assays were repeated $18 \mathrm{mo}$ later using the $\mathrm{A}$ or $\mathrm{D}$ clade version of an epitope peptide. In most cases, CTL showed preferential recognition of these peptides; in some cases, use of the A/D clade peptides allowed detection of responses not previously elicited with the B clade version. Examples of these responses are shown in Fig. 1, and the peptide sequences are shown in Table II.
The PBMC of three donors whose HLA type was unknown at the time of the blood sample were restimulated using a mixture of modified vaccinia Ankara recombinants (MVAs) expressing A, C, and D clade gag genes (Dorrell, L., C. O'Callaghan, W. Britton, S. Hambleton, A.J. McMichael, G.L. Smith, S.L. Rowland-Jones, and T. Blanchard, manuscript submitted for publication), then tested on autologous B cell lines infected with each recombinant vaccinia. One donor (ML1482) showed a reproducible CTL response to D clade gag (Fig. 2) but did not recognize the other clades.

Identification of novel HLA-A*6802- and B18-restricted epitopes in protease, reverse transcriptase, and gag. HLA-A*6802-

Table II. Preferential Recognition of Clade A or D Variants of Previously Defined Clade B HIV-1 CTL Epitopes by CTL Generated from the Resistant Nairobi Cohort

\begin{tabular}{|c|c|c|c|c|c|c|c|}
\hline Donor & Restriction & Epitope & Clade A & & Clade B & & Clade D \\
\hline ML 1250 & A2 & p17 (A) & SLFNTVATL & $>$ & SLYNTVATL & & \\
\hline ML 1362 & A2 & pol (A) & ILKDPVHG & $>$ & ILKEPVHGV & & \\
\hline \multirow[t]{2}{*}{ ML 1490} & B14 & p24 & DRFFKTLRA & $>$ & DRFYKTLRA & & \\
\hline & B49 & nef & & & YPLTGWCY & $<$ & YPLTFGWCF \\
\hline ML 1498 & B14 & p24 & DLNNMLNI & $>$ & DLNTMLNTV & & \\
\hline ML 1524 & B35 & p24 & PPIPVGDIY & $>$ & PPIPVGEIY & & \\
\hline
\end{tabular}

CTL from exposed seronegative donors set up using on either the B clade epitope or the A/D equivalent show preferential recognition of the peptide from the African clades. 


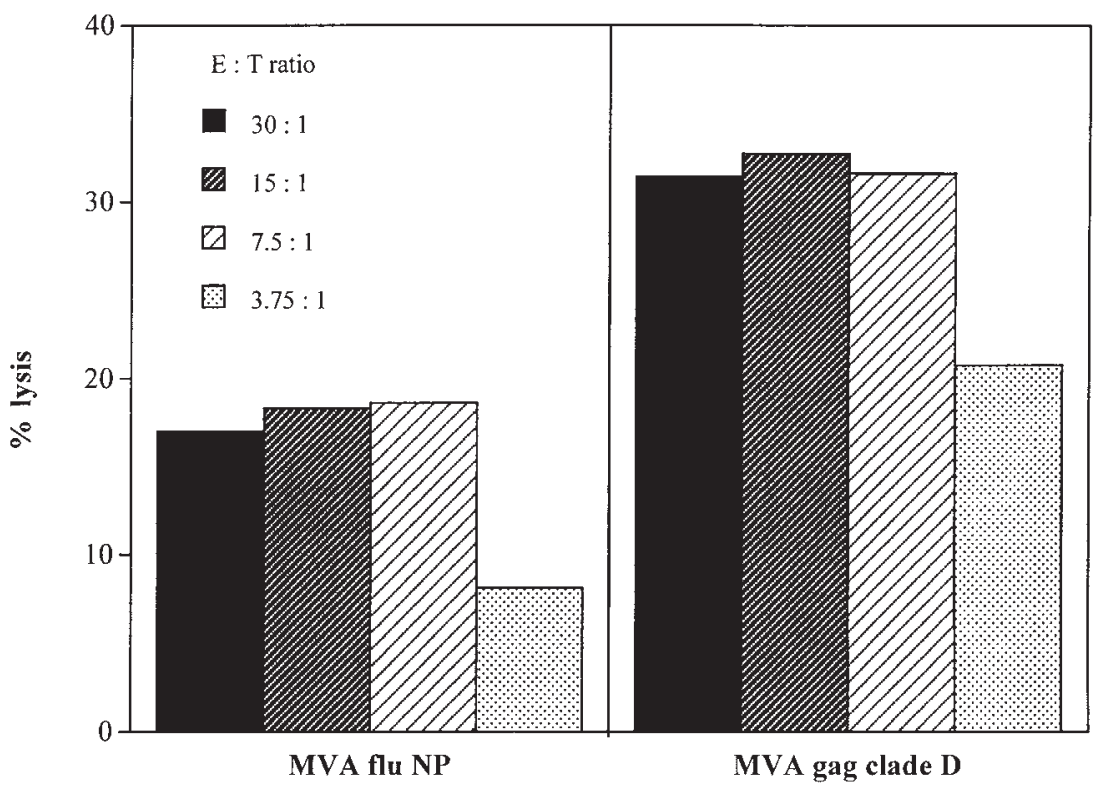

Figure 2. CTLs were established from donor ML1482 by culturing PBMC with modified vaccinia Ankara $(M V A)$ expressing clade $\mathrm{D}$ gag, at an moi of $1 \mathrm{pfu} / 30$ PBMC in the presence of IL-2. After $2 \mathrm{wk}$, the culture was tested for recognition of autologous B cells infected with MVA (moi 10 $\mathrm{pfu} /$ cell) expressing either clade D gag (right) or influenza A nucleoprotein (left). restricted CTL responses were identified from a bulk culture established from an HIV-infected Gambian donor, FS (HLAA*6802, *7401, B17, 18) and used to screen a panel of 49 predicted A*6802-restricted A and D clade epitopes. Four were recognized: one in p17, 124-132, QVSQNYPIV, (clade B/D), two in the protease 85-93, DTVLEEMNL (clade B/D) and 5866, ITLWQRPLV (conserved in all clades), and one in reverse transcriptase, 518-526, DVKQLTEVV (clade A) (Fig. 3). CTL bulk cultures were established from a further seven HIVseropositive Kenyan donors with $\mathrm{A}^{*} 6802$, and the recognition of all four epitopes was confirmed using target cells matched only through HLA-A $* 6802$.

An HLA-B*1801-restricted response to gag was identified using bulk cultures from two HIV-1-infected Caucasian donors and mapped to a 10-mer of sequence FRDYVDRFYK, p24 291-300. This lies in a highly conserved region of the gag protein, where it overlaps a number of epitopes presented by several other class I molecules (29).

$H L A-A * 6802-$ restricted $C T L$ in the resistant cohort. CTL responses to the $A^{*} 6802$ peptides were assessed in eight of the resistant cohort. Two donors made reproducible responses of $>10 \%$ specific lysis to the protease epitope, DTVLEEMNL; these donors also made CTL response through other class I alleles (Table I). Equivocal responses (i.e., 5-10\% specific lysis in more than one assay) were made to this epitope and to the second protease epitope in three further donors. It was not possible to test CTL responses in peptide-stimulated cultures by using the B18 epitope, although a strong Elispot response was detected using frozen PBMCs from donor 887, as described below.

CTL frequency assessed by Elispot assays. Elispot assays were carried out using fresh or frozen PBMC from nine donors, and the positive results are shown in Fig. 4. This estimates peptide-specific CTL frequencies at between 1:50,000 and 1:3,200 in six donors, four of whom had previously been tested for CTL activity by using peptide-stimulated cultures of fresh PBMC. For two donors, the Elispot assays confirmed previous CTL results, but in the others, activity was elicited by Elispot that had been absent (ML 935) or equivocal (ML 1437) in CTL cultures. The strongest response was to the B18 p24

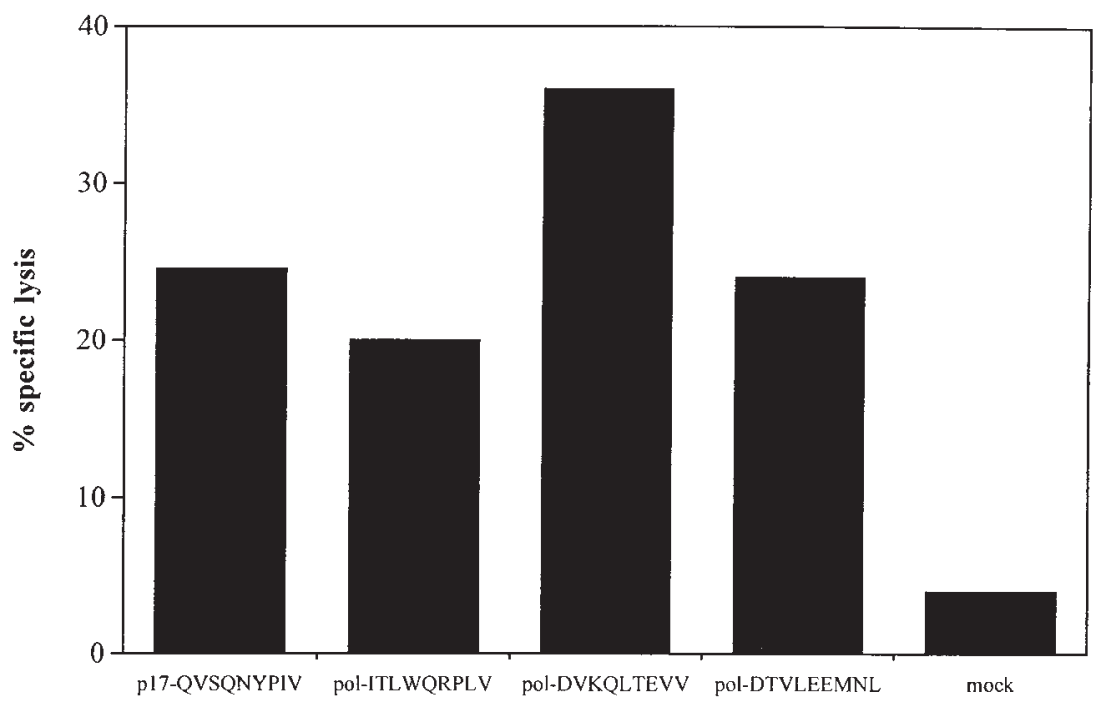

Figure 3. A CTL bulk culture from HIV-infected Gambian donor FS was tested for recognition of a panel of 49 peptides from the A and D clade consensus sequences of HIV gag, pol, and nef, which were predicted to contain the required motif for HLA-A*6802. After an initial screening on pools of peptides, individual peptides from the pools were tested. This assay shows the results of an experiment to confirm recognition of the four positive peptides identified from these screening experiments. Bulk CTL were used at E/T ratio of 40:1, and the target cells were autologous B cells pulsed with peptides at $10 \mu \mathrm{M}$. 


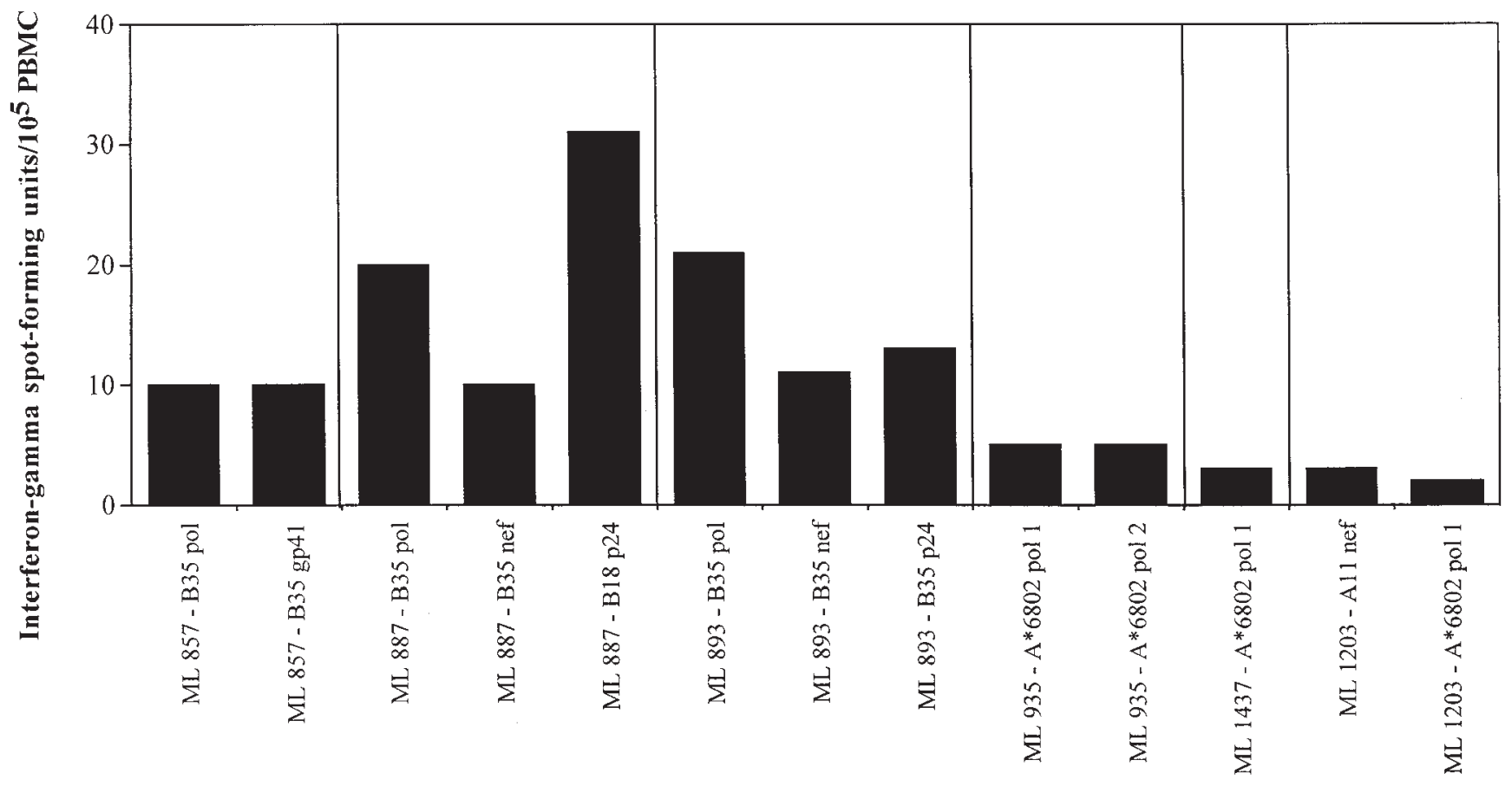

Figure 4. PBMC from different donors were cultured overnight with optimized HIV epitope peptides selected on the basis of their class I haplotype in a standard IFN- $\gamma$ Elispot assay. The results shown are the positive results for six different donors, where each bar represents the number of spots produced by $10^{5} \mathrm{PBMC}$ with each peptide at $10 \mu \mathrm{M}$, after subtraction of the no peptide controls.

peptide in donor ML887, for whom CTL cultures had not been possible.

Control studies were performed using cells from six lowrisk laboratory workers with HLA-A*0201, A*1101, A*6802, $\mathrm{B} 18$, and $\mathrm{B} 35$ and a total of 13 different HIV epitope peptides. There were no responses to any of the HIV peptides, although one donor responded to an A2-restricted influenza epitope (spot forming units [SFU] $=35 / 10^{5} \mathrm{PBMC}$ ) and another to an A2-restricted EBV epitope (SFU $\left.=61 / 10^{5} \mathrm{PBMC}\right)$.

\section{Discussion}

Although important observations about potential mechanisms of resistance to HIV infection have been made in several exposed seronegative cohorts, the Nairobi cohort is striking for both the intensity and variety of HIV exposure in the women. The extent of exposure, daily over many years, and the diversity of potential infecting strains of HIV are certainly the greatest reported anywhere in the world. Thus, an understanding of how the handful of women who remain seronegative have resisted HIV infection, in some instances for more than a decade, is of great significance towards unravelling the mechanisms of protective immunity to this virus. Resistance in this cohort cannot be attributed to any known behavioral or demographic factors (8); therefore, attention has turned to immunological and genetic mechanisms. These studies demonstrate a potential role for HIV-specific CTL in mediating protection and make it unlikely that coreceptor polymorphism is an important factor.

The CTL studies reported here used a very sensitive technique for eliciting memory peptide-specific CTL (26), which generated HIV-specific CTL from just under half the women studied; however, this is likely to be an underestimate. Al- though there is now an extensive database of CTL epitopes for a range of HLA types (13), these have largely been defined in Western cohorts consisting predominantly of Caucasians infected with clade B virus. Since CTL can be exquisitely sensitive to single amino acid substitutions (30), interclade variation between CTL epitopes makes it likely that some epitopes are unique to particular clades; this article presents some novel A and D clade epitopes, and work is under way to define further epitopes in donors infected with African strains of HIV (Dorrell, L., T. Dong, G.S. Ogg, S. Lister, S. McAdam, T. Rostron, C. Conlon, A.J. McMichael, and S.L. Rowland-Jones, manuscript submitted for publication). Thus, the use of B clade reagents to elicit CTL may fail to detect strong responses to unique epitopes in African HIV-1 clades. This is supported by the fact that stronger CTL responses could be elicited using A and D clade versions of previously defined B clade epitopes. A further limitation is that most epitopes have been mapped for Caucasian class I HLA molecules, and little is known about HIV antigen presentation through common African alleles. In this study, we describe epitopes presented by HLA-A*6802, which is the common African subtype of A28 and rare in Caucasians. Thus, we cannot exclude the presence of CTL in the remainder of the cohort to epitopes that are either unique to a particular clade or restricted by African HLA molecules for which epitope mapping has not been carried out. However, the responses detected in these women were largely to conserved epitopes, which logically are more likely to mediate protection against the diverse range of HIV strains that they encounter. Once primed these responses could be boosted by continuing exposure; this would explain why CTLs are detected repeatedly in the women, whereas they appear to be transient after single exposure, such as after needle-stick injury (31) or perinatal exposure (32). 
Both class I and II HLA alleles are associated with reduced risk of HIV-1 infection (MacDonald, K.S., K.R. Fowke, J. Kimani, V.A. Dunand, N.J.D. Nagelkerke, T.B. Ball, J. Oyugi, E. Njagi, L. Gaur, R.C. Brunham, J. Wade, S.L. Rowland-Jones, E. Ngugi, J.J. Bwayo, and F.A. Plummer, manuscript submitted for publication); the strongest protective associations with individual class I molecules are with HLA-A*6802, A*0202, and B18. One interpretation would be that these class I HLA molecules are restricting elements for particularly efficient HIV-specific CTL responses or present epitopes, which are highly conserved between HIV-1 variants. We describe here novel CTL epitopes presented by HLA-A*6802 and B18 that lie in conserved regions of the virus, providing some support for the latter hypothesis. The B18 epitope lies in the remarkably conserved major homology region of gag p24 (29), which is critically important in viral particle assembly (33). Two of the $A * 6802$ epitopes are in the protease, where CTL epitopes have not previously been defined; these may also be regions of the virus where mutability is limited by functional constraints. Further studies are necessary to determine whether or not CTL responses through HLA-B18 and A*6802 are more effective than those through other class I alleles; however, in these studies, we detected strong CTL using several other HLA molecules, while the responses through A*6802 were relatively weak. Another observation in the HLA studies is that a supermotif that comprises some A2 subtypes (A*0202,*0205, and *214) and $A * 6802$ is strongly associated with HIV resistance on multivariate analysis. Although distinct peptide-binding motifs are recognized for individual class I molecules, there is a degree of overlap in peptide-binding ability between related alleles, which can therefore form a functional superfamily. Extensive overlap in peptide presentation was recently demonstrated for HIV-specific CTL restricted by members of the A3 superfamily (34), where the same epitopes could be presented by HLA-A 3 and A11, and even recognized when presented by one molecule by CTL clones restricted by the other allele. Functional overlap between members of the A2 and A28 superfamily has been found in some $(35,36)$ but not all $(24)$ studies. More recently, the same EBV epitope was shown to be presented by cells expressing several members of this class I family, including $A * 0201, A * 0202, A * 6802$, and A*6901 (37). These studies show that HLA-A*202 can bind many of the same peptides as HLA-A*201, and in this study, we demonstrate recognition of epitopes previously defined for $A * 201$ in donors with $A * 202$. Furthermore, one of the $A * 6802$ epitopes is also restricted by $A^{* 7401}$ (not shown), and we have found that another is presented by A26 (Dorrell, L., T. Dong, G.S. Ogg, S. Lister, S. McAdam, T. Rostron, C. Conlon, A.J. McMichael, and S.L. Rowland-Jones, manuscript submitted for publication); although these class I molecules have not been ascribed to the A2 superfamily, these observations reinforce the concept of cross-reactivity between some class I molecules for HIV epitopes.

There is now a substantial body of evidence that $T$ cell responses to HIV can be elicited from exposed individuals in the absence of detectable infection, without the development of circulating HIV-specific IgG antibodies, which are the hallmark of persistent HIV infection $(2,38)$. Animal experiments point to $\mathrm{CD}^{+}$cellular responses as potential mediators of protection against HIV. SCID mice reconstituted with PBMC from exposed seronegative individuals were protected against $\mathrm{HIV}$ infection even though their $\mathrm{CD} 4^{+}$cells were susceptible to HIV infection in vitro; this protection resided in the $\mathrm{CD}^{+}$ cell population, which showed HIV antigen-specific secretion of IFN- $\gamma$ in an Elispot assay (39). Macaques exposed to but not infected with HIV-2 were protected from subsequent mucosal challenge with SIV; the protected animals had SIV/HIV-specific CTL activity in the absence of serum antibodies (40). It seems likely that transient infection with replication-competent virus is necessary to prime these cellular responses, but this has not yet been unequivocally demonstrated.

One of the most important mechanisms of HIV resistance in Caucasians is the possession of mutations that abolish cellsurface expression of the coreceptor for most primary HIV strains, CCR5 $(15,41)$. The CCR5 $\Delta 32$ mutation has not been found in Africans (20), and an extensive search in this cohort has not revealed any additional coding mutations that might affect CCR5 coreceptor function, such as the recently described m303 substitution (41). The levels of CCR5 expression on cells from these women are generally high, and their cells are extremely susceptible to infection with both NSI and SI strains of virus (22), which makes an as yet unidentified coreceptor abnormality most unlikely.

Thus, in this most highly exposed of cohorts, the distinguishing feature of the resistant group is the presence of circulating broadly cross-reactive HIV-specific CTL in the absence of detectable HIV infection. These findings suggest that resistance in this group is probably immune mediated and supports the concept that a successful vaccine against diverse strains of HIV infection will have to elicit a broad range of HIV-specific CTL responses (42).

\section{Acknowledgments}

We are grateful to Philip Thornton-Evison and Tim Rostron for technical help, and to the staff at the Pumwani-Majengo clinic for help with collecting the blood samples. We thank Dr. Adrian Minty (Sanoffi-Labege) for kindly providing the rIL-7.

This work was supported by the Medical Research Councils of the UK and Canada, and the Elizabeth Glaser Paediatric AIDS Foundation. S. Rowland-Jones is an MRC Senior Fellow and an Elizabeth Glaser Scientist, and F.A. Plummer is a Senior Scientist of the Medical Research Council of Canada.

\section{References}

1. Clerici, M., and G. Shearer. 1993. A Th1 $\rightarrow$ Th2 switch is a critical step in the aetiology of HIV infection. Immunol. Today. 14:107-111.

2. Rowland-Jones, S.L., and A.J. McMichael. 1995. Immune responses in HIV-exposed seronegatives: have they repelled the virus? Curr. Opin. Immunol. 7:448-455.

3. Mazzoli, S., D. Trabbatoni, S. Lo Caputo, S. Piconi, C. Ble, F. Meacci, S. Ruzzante, A. Salvi, F. Semplici, R. Longhi, et al. 1997. HIV-specific mucosal and cellular immunity in HIV-seronegative partners of HIV-seropositive individuals. Nat. Med. 3:1250-1257.

4. Rowland-Jones, S.L., J. Sutton, K. Ariyoshi, T. Dong, F.M. Gotch, S. McAdam, D. Whitby, S. Sabally, A. Gallimore, T. Corrah, et al. 1995. HIV-specific cytotoxic T cells in HIV-exposed but uninfected Gambian women. Nat. Med. 1:59-64.

5. Moses, S., F.A. Plummer, E.N. Ngugi, N.J. Nagelkerke, A.O. Anzala, and J.O. Ndinya-Achola. 1991. Controlling HIV in Africa: effectiveness and cost of an intervention in a high frequency STD transmitter core group. AIDS. 5:407411.

6. Anzala, O.A., N.J. Nagelkerke, J.J. Bwayo, D. Holton, S. Moses, E.N. Ngugi, J.O. Ndinya-Achola, and F.A. Plummer. 1995. Rapid progression to disease in African sex workers with human immunodeficiency virus type 1 infection. J. Infect. Dis. 171:686-689.

7. Anzala, A.O., T.B. Ball, T. Rostron, S.J. O'Brien, F.A. Plummer, the Nairobi HIV study group, and S.L. Rowland-Jones. 1998. The 64I allele of the CCR2 chemokine receptor is strongly associated with delayed disease progres- 
sion in a cohort of African prostitutes. Lancet. 351:1632-1633.

8. Fowke, K., N. Nagelkerke, J. Kimani, J.N. Simonsen, A.O. Anzala, J.J. Bwayo, K.S. MacDonald, E.N. Ngugi, and F.A. Plummer. 1996. Resistance to HIV-1 infection amongst persistently seronegative prostitutes in Nairobi, Kenya. Lancet. 348:1347-1351.

9. Ferrari, G., W. Humphrey, M.J. McElrath, J.L. Excler, A.M. Duliege, M.L. Clements, L.C. Corey, D.P. Bolognesi, and K.J. Weinhold. 1997. Clade B-based HIV-1 vaccines elicit cross-clade cytotoxic T lymphocyte reactivities in uninfected volunteers. Proc. Natl. Acad. Sci. USA. 94:1396-1401.

10. Cao, H., P. Kanki, J.L. Sankale, S.A. Dieng, G.P. Mazzara, S.A. Kalams, B. Korber, S. Mboup, and B.D. Walker. 1997. Cytotoxic T-lymphocyte crossreactivity among different human immunodeficiency virus type 1 clades: implications for vaccine development. J. Virol. 71:8615-8623.

11. Betts, M.R., J. Krowka, C. Santamaria, K. Balsamo, F. Gao, G. Mulundu, C. Luo, N. N'Gandu, H. Sheppard, B.H. Hahn, et al. 1997. Cross-clade human immunodeficiency virus (HIV)-specific cytotoxic T-lymphocyte responses in HIV-infected Zambians. J. Virol. 71:8908-8911.

12. McAdam, S., P. Kaleebu, P. Krausa, P. Goulder, N. French, B. Collin, T. Blanchard, J. Whitworth, A. McMichael, and F.M. Gotch. 1998. Cross-clade recognition of $\mathrm{p} 55$ by CTL in HIV-1 infection. AIDS. 12:571-579.

13. Korber, B., J. Moore, C. Brander, B. Walker, B. Haynes, and R. Koup. 1997. HIV Molecular Immunology Database. Theoretical Biology and Biophysics Group, Los Alamos National Laboratory, Los Alamos, NM.

14. Poss, M., J. Gosink, E. Thomas, J.K. Kreiss, J. Ndinya-Achola, K. Mandaliya, J. Bwayo, and J. Overbaugh. 1997. Phylogenetic evaluation of Kenyan HIV type 1 isolates. AIDS Res. Hum. Retroviruses. 13:493-499.

15. Liu, R., W.A. Paxton, S. Choe, D. Ceradini, S.R. Martin, R. Horuk, M.E. MacDonald, H. Stuhlman, R.A. Koup, and N.R. Landau. 1996. Homozygous defect in HIV-1 coreceptor accounts for resistance of some multiplyexposed individuals to HIV-1 infection. Cell. 88:7-20.

16. Paxton, W.A., S.R. Martin, D. Tse, T.R. O'Brien, J. Skurnick, N.L. Van Devanter, N. Padian, J.F. Braun, D.P. Kotler, S.M. Wolinsky, et al. 1996. Relative resistance to HIV-1 infection of CD4 lymphocytes from persons who remain uninfected despite multiple high-rish sexual exposures. Nat. Med. 2:412-417.

17. Huang, Y., W.A. Paxton, S.M. Wolinsky, A.U. Neumann, L. Zhang, T. He, S. Kang, D. Ceradini, Z. Jin, K. Yazdanbakhsh, et al. 1996. The role of a mutant CCR5 allele in HIV-1 transmission and disease progression. Nat. Med. 2:1240-1243.

18. Michael, N.L., G. Chang, L. Louie, J.R. Mascola, D. Dondero, D.L. Birx, and H.W. Sheppard. 1997. The role of viral phenotype and CCR-5 gene defects in HIV-1 transmission and disease progression. Nat. Med. 3:338-340.

19. Dean, M., M. Carrington, C. Winkler, G.A. Huttley, M.W. Smith, R. Allikmets, J.J. Goedert, S.P. Buchbinder, E. Vittinghoff, E. Gomperts, et al. 1996. Genetic restriction of HIV-1 infection and progression to AIDS by a deletion allele of the CKR5 structural gene. Hemophilia Growth and Development Study, Multicenter AIDS Cohort Study, Multicenter Hemophilia Cohort Study, San Francisco City Cohort, ALIVE Study. Science. 273:1856-1862.

20. Martinson, J.J., N.H. Chapman, D.C. Rees, Y.-T. Liu, and J.B. Clegg. 1997. Global distribution of the CCR5 gene 32 base-pair deletion. Nat. Genet. 16:100-103.

21. Samson, M., F. Libert, B.J. Doranz, J. Rucker, C. Liesnard, C.-M. Farber, S. Saragosti, C. Lapumeroulie, J. Cognaux, C. Forceille, et al. 1996. Resistance to HIV-1 infection in caucasian individuals bearing mutant alleles of the CCR-5 chemokine receptor gene. Nature. 382:722-725.

22. Fowke, K., T. Dong, S.L. Rowland-Jones, J. Oyugi, W.J. Rutherford, P. Krausa, J. Kimani, J. Bwayo, J.N. Simonsen, G. Shearer, et al. 1998. HIV-1 resistance in Kenyan sex workers is not associated with altered cellular susceptibility to HIV-1 infection or enhanced beta-chemokine production. AIDS Res. Hum. Retroviruses. 14:1521-1530.

23. Bunce, M., C.M. O’Neill, M.C. Barnardo, P. Krausa, M.J. Browning, P.J. Morris, and K.I. Welsh. 1995. Phototyping: comprehensive DNA typing for HLA-A, B, C, DRB1, DRB3, DRB4, DRB5 \& DQB1 by PCR with 144 primer mixes utilizing sequence-specific primers. Tissue Antigens. 46:355-367.

24. Barouch, D., T. Friede, S. Stevanovic, L. Tussey, K. Smith, J.S. Rowland, V. Braud, A. McMichael, and H.G. Rammensee. 1995. HLA-A2 subtypes are functionally distinct in peptide binding and presentation. J. Exp. Med. 182: 1847-1856.
25. Nixon, D.F., A.R.M. Townsend, J.G. Elvin, C.R. Rizza, J. Gallwey, and A.J. McMichael. 1988. HIV-1 gag-specific cytotoxic T lymphocytes defined with recombinant vaccinia virus and synthetic peptides. Nature. 336:484-487.

26. Lalvani, A., T. Dong, G. Ogg, A.A. Patham, H. Newell, A.V. Hill, A.J. McMichael, and S. Rowland-Jones. 1997. Optimization of a peptide-based protocol employing IL-7 for in vitro restimulation of human cytotoxic T lymphocyte precursors. J. Immunol. Methods. 210:65-77.

27. Lalvani, A., R. Brookes, S. Hambleton, W.J. Britton, A.V. Hill, and A.J. McMichael. 1997. Rapid effector function in CD8+ memory T cells. J. Exp. Med. 186:859-865.

28. Lalvani, A., R. Brookes, R.J. Wilkinson, A.S. Malin, A.A. Pathan, P. Andersen, H. Dockrell, G. Pasvol, and A.V. Hill. 1998. Human cytolytic and interferon gamma-secreting CD8+ T lymphocytes specific for Mycobacterium tuberculosis. Proc. Natl. Acad. Sci. USA. 95:270-275.

29. Ogg, G.S., T. Dong, P. Hansasuta, L. Dorrell, J. Clarke, R. Coker, G. Luzzi, C. Conlon, A.J. McMichael, and S.L. Rowland-Jones. 1998. Four novel CTL epitopes in the highly-conserved MHR region of HIV-1 gag, restricted by $\mathrm{B} * 4402, \mathrm{~B} * 1401, \mathrm{~A} * 2601$ and $\mathrm{B} * 70$. AIDS. 12:1561-1563.

30. Phillips, R.E., S.L. Rowland-Jones, D.F. Nixon, F.M. Gotch, J.P. Edwards, A.O. Ogunlesi, J.G. Elvin, J.A. Rothbard, C.R. Bangham, C.R. Rizza, et al. 1991. Human immunodeficiency virus genetic variation that can escape cytotoxic T cell recognition. Nature. 354:453-459.

31. Pinto, L.A., J. Sullivan, J.A. Berzofsky, M. Clerici, H.A. Kessler, A.L. Landay, and G.M. Shearer. 1995. ENV-specific cytotoxic T lymphocyte responses in HIV seronegative health care workers occupationally exposed to HIV-contaminated body fluids. J. Clin. Invest. 96:867-876.

32. Rowland-Jones, S.L., D.F. Nixon, M.C. Aldhous, F. Gotch, K. Ariyoshi, N. Hallam, J.S. Kroll, K. Froebel, and A.J. McMichael. 1993. HIV-specific CTL activity in an HIV-exposed but uninfected infant. Lancet. 341:860-861.

33. Mammano, F., A. Ohagen, S. Hoglund, and H.G. Gottlinger. 1994. Role of the major homology region of human immunodeficiency virus type 1 in virion morphogenesis. J. Virol. 68:4927-4936.

34. Threlkeld, S.C., P.A. Wentworth, S.A. Kalams, B.M. Wilkes, D.J. Ruhl, E. Keogh, J. Sidney, S. Southwood, B.D. Walker, and A. Sette. 1997. Degenerate and promiscuous recognition by CTL of peptides presented by the MHC class I A3-like superfamily: implications for vaccine development. J. Immunol. 159:1648-1657.

35. del Guercio, M.-F., J. Sidney, G. Hermanson, C. Perez, H.M. Grey, R.T. Kubo, and A. Sette. 1995. Binding of a peptide antigen to multiple HLA alleles allows definition of an A2-like supertype. J. Immunol. 154:685-693.

36. Bertoni, R., J. Sidney, P. Fowler, R.W. Chesnut, F.V. Chisari, and A. Sette. 1997. Human histocompatibility leukocyte antigen-binding supermotifs predict broadly cross-reactive cytotoxic $\mathrm{T}$ lymphocyte responses in patients with acute hepatitis. J. Clin. Invest. 100:503-513.

37. Khanna, R., S.R. Burrows, J. Nicholls, and L.M. Poulsen. 1998. Identification of cytotoxic T cell epitopes within Epstein-Barr virus (EBV) oncogene latent membrane protein 1 (LMP1): evidence for HLA A2 supertype-restricted immune recognition of EBV-infected cells by LMP1-specific cytotoxic T lymphocytes. Eur. J. Immunol. 28:451-458.

38. Shearer, G.M., and M. Clerici. 1996. Protective immunity against HIV infection: has nature done the experiment for us? Immunol. Today. 17:21-24.

39. Zhang, C., Y. Cui, S. Houston, and L.J. Chang. 1996. Protective immunity to HIV-1 in SCID/beige mice reconstituted with peripheral blood lymphocytes of exposed but uninfected individuals. Proc. Natl. Acad. Sci. USA. 93: $14720-14725$.

40. Putkonen, P., B. Makitalo, D. Bottiger, G. Biberfeld, and R. Thorstensson. 1997. Protection of human immunodeficiency virus type 2-exposed seronegative macaques from mucosal simian immunodeficiency virus transmission. $J$. Virol. 71:4981-4984.

41. Quillent, C., E. Oberlin, J. Braun, D. Rousset, G. Gonzalez-Canali, P. Metais, L. Montagnier, J.-L. Virelizier, F. Arenzana-Seisdedos, and A. Beretta 1997. HIV-1-resistance phenotype conferred by combination of two separate inherited mutations of CCR5 gene. Lancet. 351:14-18.

42. Ada, G.L., and M.J. McElrath. 1997. HIV-1 vaccine-induced cytotoxic T-cell responses: potential role in vaccine efficacy. AIDS Res. Hum. Retroviruses. 13:205-210. 